\title{
Article \\ Computational Fluid Dynamics (CFD) Simulation of Inclusion Motion under Interfacial Tension in a Flash Welding Process
}

\author{
Md Irfanul Haque Siddiqui ${ }^{1}$, Hassan Alshehri ${ }^{1}$, Jamel Orfi ${ }^{1,2}$, Masood Ashraf Ali ${ }^{3}$ and Dan Dobrotă ${ }^{4, *}$ (i) \\ 1 Mechanical Engineering Department, King Saud University, Riyadh 11421, Saudi Arabia; \\ msiddiqui2.c@ksu.edu.sa (M.I.H.S.); hashehri@ksu.edu.sa (H.A.); orfij@ksu.edu.sa (J.O.) \\ 2 KA.CARE Energy Research and Innovation Center, Riyadh 11451, Saudi Arabia \\ 3 Department of Mechanical Engineering, College of Engineering, Prince Sattam Bin Abdulaziz University, \\ Al-Kharj 16273, Saudi Arabia; mas.ali@psau.edu.sa \\ 4 Department of Industrial Engineering and Management, Faculty of Engineering, \\ Lucian Blaga University of Sibiu, 550024 Sibiu, Romania \\ * Correspondence: dan.dobrota@ulbsibiu.ro; Tel.: +40-722-446-082
}

Citation: Siddiqui, M.I.H.; Alshehri, H.; Orfi, J.; Ali, M.A.; Dobrotă, D. Computational Fluid Dynamics (CFD) Simulation of Inclusion Motion under Interfacial Tension in a Flash Welding Process. Metals 2021, 11, 1073. https://doi.org/10.3390/ met11071073

Academic Editor: António Pereira

Received: 7 June 2021

Accepted: 30 June 2021

Published: 3 July 2021

Publisher's Note: MDPI stays neutral with regard to jurisdictional claims in published maps and institutional affiliations.

Copyright: (c) 2021 by the authors. Licensee MDPI, Basel, Switzerland. This article is an open access article distributed under the terms and conditions of the Creative Commons Attribution (CC BY) license (https:// creativecommons.org/licenses/by/ $4.0 /)$.

\begin{abstract}
Non-metallic inclusions particles are detrimental to the mechanical properties of a material. It is very important to understand the motion behavior of inclusion particles in molten metal. The motion behavior of non-metallic inclusion particles during weld pool solidification and their distribution in joint areas is dependent on various factors. In the alternative current (AC) flash welding process, inclusions motions are dependent on welding plate movement, interfacial tensions, etc. Apart from this, the temperature of the molten metal in the welding zone and the size of inclusion particles also play an important role. Secondly, the Marangoni forces are developed due to interfacial tension which affects the movement of inclusion particles at the solid-liquid interface in a solidifying welding pool. The interfacial tension varies with the change in surfactant concentration and other factors. In this work, the effect of upsetting rate and interfacial tension on alumina inclusions has been studied. The interfacial tension controls the pushing and engulfment of non-metallic inclusions at the solid-liquid interface. A two-dimensional multiphase mathematical model has been developed to study the inclusion motion behavior at the solid-liquid interface in a solidifying weld pool. The numerical model has been developed by adding the volume of fluid method (VOF), a dynamic mesh model and discrete phase model for a realistic approach. The predicted results show that the upsetting setting parameters have a substantial effect on the overall non-metallic inclusion motion. The inclusions were seen moving away from the welded joint due to the high up-setting rate. The results also reveal that the inclusions were engulfed by the solidification front under the effect of the strong interfacial tension between the non-metallic inclusions and the molten steel.
\end{abstract}

Keywords: inclusion; interfacial tension; welding; CFD; simulation; Marangoni force

\section{Introduction}

AC flash butt welding is a method to join two ends of metal pieces. The ends of metal pieces are pressed together and welded by flash arc. For efficient operation, one end is clamped by a movable plate, while the other is fixed by a clamping mechanism. In this welding process, the end of the part to be welded is connected to the secondary circuit of the transformer. Initially, the two ends of the metal parts are preheated by an electrical circuit. The AC current is applied to the two metal parts and both parts are bought together repeatedly to complete the high current electrical circuit. In a few seconds, the temperature at the two ends is sufficiently high to develop flash. At this stage, a flash is generated and the two ends rapidly melt. After that, enough heat is produced to melt the metal and form a weld pool between the two parts. In the next step, the metal pieces are pressed by high force which leads to the weld pool being suppressed and, hence, trapped contamination and oxide inclusions are pressed out from the weld joint. The surface of the 
movable piece is butted against another fixed surface with a higher force in the final phase of the operation. Finally, the workpiece is cooled at room temperature and this method produces a high-strength welded joint. The extrusion of molten metal oxides and other impurities onto the outer surfaces is aided by this upsetting operation, which improves weld efficiency [1]. This welding method produces a strong welded joint with minimum welding defects. Hence, this method is widely applied in welding thicker parts of metals. Flash welding is popular in various industrial sectors, such as the automotive industry, sheet welding, hot rolled coils, shipyard construction, pipeline construction, railways, etc. [2,3]. AC flash welding is generally used for welding steel materials but sometimes also used for welding aluminum, titanium and nickel-based alloys.

In recent years, a variety of higher-strength steel materials has been used in various forays of the industry, making it more difficult to preserve the durability and mechanical properties of welded joints [4-10]. The microinclusions are not visible with the naked eye but have to be seen under a microscope. Inclusions are normally in the size range of one to a hundred microns. The inclusion sizes, their distribution and chemistry and types of inclusions influence the grain size and phases. In certain cases, they act as the nuclei for other phases to form and influence the mechanical properties, for example, decreasing the toughness, ductility and strength. It is well established from previously reported in literature that welding parameters affect mechanical properties and contamination during the welding process is also detrimental to welding quality of high-strength lowalloy steel (HSLA) [11]. During the welding process, the weld pool is contaminated by foreign materials and further oxidation of melt contributes more impurities [12,13]. These contaminations and impurities in terms of oxide inclusions severely hamper the hardness, strength, fatigue life, surface and microstructure morphology and final weld quality. Lu et al. [14] investigated the surface morphology of HSLA 590CL steel. They carried out flash welding of two parts of a wheel rim made from HSLA 590CL steel. It was reported that non-metallic inclusion particles were discovered at the fractured surface during microstructural analysis. They concluded that the fracture of the wheel rim happened due to the presence of non-metallic inclusion particles in the steel matrix which created microcracks. Further, Shajan et al. $[15,16]$ reported that the formation of oxide inclusions reduces and significantly affects the hardness of the weld joint. Most of the time, flash welded joints fail due to crack formation $[17,18]$. Hence, setting flash welding parameters and removal of oxide inclusions are important tasks to improve the final weld quality and for a sustainable steel business.

It is imperative to examine the effects of welding parameters on oxide inclusion distribution in AC flash welded joints to ensure the quality of welded joints. As a result, it is important to look into the effects of upsetting rate and inclusion size on the distribution of inclusions in flash welded joints. Ichiyama and Kodama [19] reported that various kinds of oxide inclusions are formed during the flash welding process, such as oxides of silicon, aluminum, manganese, etc. Some fractions of oxide inclusions inside the weld pool are expelled during the final stage of the welding process, however, a significant number of oxides remain inside the welded joints. They also reported that steels with more inclusion particles had lower hardness. Further, they investigated the expulsion of oxide inclusions during the final upsetting process by adjusting current density. They concluded that a higher unsettling current promotes molten layer extrusion and inclusion-exclusion from the weld joint. Additionally, the different parameters involved in the flash butt welding process were analyzed by Kim et al. [1].

They found that at a low upset rate, oxide inclusions were not separated from the center of the weld joint. In another work, Lu et al. [20] demonstrated that increasing the upset pressure improved the separation and removal of impurities from the main center of welded joints. It is also reported by various studies that oxide inclusions are formed in welded joints due to the open welding environmental conditions [21-24]. The amount of oxides generated is thought to increase as the flashing time lengthens [23]. $\mathrm{Xi}$ et al. [24] reported that excessive flashing and the duration are the reasons for oxide 
impurity formations and entrapment in flash weld joints. In addition to this, pressure applied to metal pieces during the last step of the weld process is also a major parameter which greatly influences the entrapment condition of oxide inclusions [25,26].

Non-metallic particles embedded in the weld metal or weld interface are called inclusions. Insufficient welding technology, poor joint contact, or both, may produce inclusions. The sharp notches between the weld boundaries or between the weld beads help slag inclusion. When using a coated electrode, a layer of slag will form on the top of the weld, which must be cleaned up after welding. The hollows and sharp corners seem to capture slag fragments. Slag removal involves chisel hammers or wire brushes, and the difficulty varies depending on the type of electrode coating. If the welding spatter is not removed properly, welding spatter inclusions may appear in the weld. Slag is the deoxidation product of the reaction between the flux, air and surface oxides because it is the residue of the flux coating. If two adjacent welds are buried without sufficient overlap and a gap is formed, the slag will get stuck in the weld. The entrained slag will not be removed until the next layer is deposited. Excessive undercuts on the weld toe or an irregular surface profile of the previous weld may even trap the slag in the cavity in the multipass weld. Single particles or longer inclusion lines are possible. Failure to properly remove slag in one weld pass and then carrying out another weld pass is the most common source of slag inclusions. Effective work strategies will help reduce risks. In closed joints, it is also important to use the correct welding process to avoid the use of thick electrodes. It is also important to prevent undercuts during welding.

The motion of inclusion particles is dependent upon various parameters. One of the most important parameters is surfactant concentration. Any change and any modification in surfactant concentration affect the interfacial tension in the liquid metal. Subsequently, interfacial tension affects the Marangoni forces applied on the non-metallic particle. It has been seen that surfactant concentration affects the interfacial tension. There may be various types of surfactants in the molten pool, for example, sulfur nitrogen-oxygen. During the solidification, the solid and liquid boundaries remove surfactant and thus there is a concentration of surfactant at the solidification boundary. The increase in surfactant concentration reduces the interfacial tension at the solid-liquid boundary. In a welding pool, there are several types of non-metallic inclusions, and, during the solidification of the weld melt pool, non-metallic inclusion is affected by the interfacial tension. It would be beneficial to see how inclusion particles are affected by the surfactant concentration. Several studies have looked into the engulfment or pushing of gas bubbles or inclusion particles by an advancing solid at the solid-liquid interface. Shibata et al. looked at the action of inclusions on the metal surface immediately in front of the solid-liquid interface [27]. Several researchers have pointed out that the Marangoni effect, which is induced by a temperature gradient or a surface-active element concentration gradient, affects bulk flow in microgravity experiments [28]. Yin and Emi [29] also reported that a low concentration of oxygen and sulfur caused a strong Marangoni flow during melt solidification. Further, according to [30-32], interfacial tension gradients at the solid-liquid interface boundary layer caused pushing and engulfment at the solid-liquid interface. They also discovered alumina inclusions in stainless steel slabs with a related propensity. The inclusion growth and dissolution in the weld pool were numerically predicted by Hong et al. [33]. In the welded region, they investigated the weld structure, size distribution and number and density of oxide inclusions. It is important to study whether Marangoni flow has a major impact on the FBW operation. Additionally, there have been several research works on simulating the welding process. The current work uses the multiphase 150 volume of fluid method along with the discrete phase concept of CFD modeling which can be found elsewhere [34-36].

The purpose of this work is to investigate the flash welding parameters, such as upsetting rate of two movable plates on the weld pool and subsequent impact on alumina inclusion entrapment. In the present work, the kinematic characteristics of the solidified thin strip weld of an SPFH590 steel plate are based on the two-dimensional CFD numerical 
model. The multiphase VOF numerical model was combined with the dynamic motion of two ends of workpieces, the discrete phase and melt solidification. Secondly, the inclusion pushing and engulfment phenomena were also investigated under the influence of interfacial tension developed due to sulfur concentrations.

\section{Experiment}

The present research work is an extension of the work carried out by Siddiqui et al. [26]. A sample of a wheel rim, which was welded by AC flash welding, was considered in their work. The wheel rim was made of SPFH590 microalloyed steel plates. The distribution of inclusions along the weld joint core was investigated and various types of oxides were revealed in the weld joint. The experimental procedure for AC flash welding is shown in Figure 1 by a schematic diagram. Initially, the two conjugate faces of steel plates are brought together, and arc flash is produced in between by an electrical alternating current. After that, a movable plate is pushed towards the other fixed plate with significant force. This procedure strongly welds two plates without adding too many impurities in the joined section. Further, a fraction of the weld pool is pushed in an outward direction during this welding process. The welding sample had dimensions of $2.4 \mathrm{~mm} \times 3.0 \mathrm{~mm}$. Our present research work is based on the simulation of the interfacial tension of SPFH590 steel and alumina inclusions. Thus, a suitable interfacial tension correlation was required. Hence, we took empirical relations from the work of Jeong et al. [37]. They experimentally developed the surface tension of SPFH590 steel and the interfacial tension between SPFH590 steel and an alumina inclusion. The surface tension of SPFH590 steel can be calculated as follows:

$\sigma_{L}=(1511+0.08277 T)-(1041-0.5156 T) \times\{\ln [1+\exp (-3.583+19846 / T)(\mathrm{wt} . \% S)]\}$

where $\sigma_{L}$ is surface tension, $T$ is temperature in $\mathrm{K}, S$ is sulfur concentration in ppm.

(a) Arcing and meting

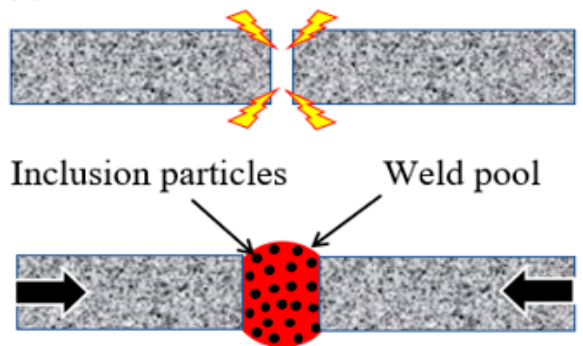

(b) Pushed

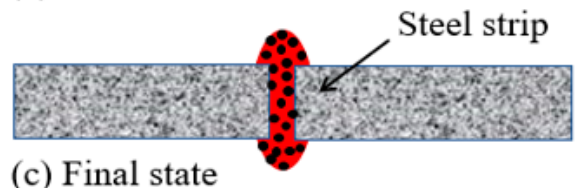

Figure 1. Representation of AC flash butt welding process. (a) arcing and melting; (b) pushed; (c) final state.

The following equation describes the interfacial stress between SPFH590 steel and an alumina inclusion.

$\begin{aligned} \sigma_{P L}=\{ & \left.3050.51+131437.97 \times(\text { wt. } \% S)-1.544 \times 10^{7}(\text { wt. } \% ~ S)^{2}-3.378 \times 10^{9}(\text { wt. } \% S)^{3}\right\} \\ & +\left\{-0.8498-79.739 \times(\text { wt. } \% S)+7655.06 \times(\text { wt. } \% S)^{2}+1.962 \times 10^{6} \times(\text { wt. } \% S)^{3}\right\} T\end{aligned}$

where $\sigma_{P L}$ is interfacial tension between SPFH590 steel and an alumina inclusion. 


\section{Numerical Modeling}

\subsection{The Governing Equation}

The numerical model has been developed to simulate the arc flash welding process and predict the inclusion motion behavior during upsetting and solidification of weld joints. The dynamic mesh model has been incorporated to develop a realistic simulation model of the squeezing of the weld pool and successive solidification processes. A two-dimensional, multiphase model has been constructed along with various other models to study the effect of weld parameters and various interfacial phenomena. The present simulation model was developed with a CFD-based mathematical model and the governing equations for mass and momentum are given as follows:

$$
\begin{gathered}
\frac{\partial \rho}{\partial t}+\nabla \cdot(\rho \vec{v})=S_{m} \\
\frac{\partial}{\partial t}(\rho \vec{v})+\nabla \cdot(\rho v \vec{v})=-\nabla p+\nabla \cdot(\overline{\bar{\tau}})+\rho \vec{g}+\vec{F}
\end{gathered}
$$

where $p$ is the static pressure, $\overline{\bar{\tau}}$ is the stress tensor, $\rho \vec{g}, S_{m}$ is the mass source term and $\vec{F}$ is the gravitational body force external body force. The solutions of the abovementioned equations are used to calculate the velocity field, pressure and temperature of the fluid in the given domain. The stress tensor $\overline{\bar{\tau}}$ is given by Equation (5).

$$
\overline{\bar{\tau}}=\mu\left[\left\{\nabla \vec{v}+\nabla \vec{v}^{T}\right\}-\frac{2}{3} \nabla \cdot \vec{v} I\right]
$$

where $\mu$ is the molecular viscosity, $I$ is the unit tensor and the second term on the right-hand side is the effect of volume dilation. The energy equation is expressed in Equation (6):

$$
\frac{\partial}{\partial t}(\rho E)+\nabla \cdot\{\vec{v}(\rho E+p)\}=\nabla \cdot\left\{k_{e f f} \nabla T-\sum_{j} h_{j} \vec{J}_{j}+\left(\overline{\bar{\tau}}_{e f f} \cdot \vec{v}\right)\right\}+S_{h}
$$

where $k_{\text {eff }}$ is the effective conductivity $\left(k+k_{t}\right.$, where $k_{t}$ is the turbulent thermal conductivity, defined according to the turbulence model being used) and $\vec{J}_{j}$ is the diffusion flux of species $j . S_{h}$ is a volumetric heat source term.

The enthalpy-porosity method was used to numerically quantify the weld pool (molten metal) solidification. The molten metal liquid fraction from 0 to 1 (also known as the mushy zone) was considered as a porous medium. The porosity of each cell has been considered to calculate the liquid fraction of the cell. Further, the solidified cells were treated as non-porous cells having a porosity fraction of one. Thus, velocities of completely solidified cells were assumed to be zero. Further, the mushy zone was modeled as a "pseudo" porous medium. This means that the mushy zone had a porosity fraction from 0 to 1 [38]. In this model, metal enthalpy has been calculated by adding the sensible enthalpy, $h$, and the latent gas, $\Delta H$ :

$$
H=h+\Delta H
$$

where

$$
h=h_{r e f}+\int_{T_{r e f}}^{T} C_{p} d T
$$

Additionally, $h_{r e f}$ is reference enthalpy, $T_{r e f}$ is reference temperature, $C_{p}$ is specific heat at constant pressure. 
Further, the liquid fraction, $£$, can be defined as:

$$
\begin{gathered}
£=0 \text { if Temperature }(T o)<\text { Solidus Temperature }(T s) \\
£=1 \text { if Temperature }(T o)>\text { Solidus Temperature }(T s) \\
£=\frac{T o-T s}{T l-T s} \text { if } T s<T<T l
\end{gathered}
$$

The weld pool's latent heat content is given as $L, \Delta H=£$. For both solids and liquids, the latent heat content may range from 0 to 1 . The value of latent heat can be obtained from [39]. Furthermore, the energy equation for solidification/melting problems is written as:

$$
\frac{\partial}{\partial t}(\rho H)+\nabla \cdot(\rho \vec{v} H)=\nabla \cdot(k \nabla T)+S
$$

where $H$ is the enthalpy and $S$ is the source term. The basic approach employed for treating melting and solidification is adding a phenomenological heat source term to the thermal energy equation. At the beginning of the calculation, the domain was initialized with a specific temperature of molten steel. The heat source term is calculated from the initial conditions.

The solution of a convection-diffusion equation for the $i$ th species predicts the local mass fraction of molten steel, sulfur material and $Y_{i}$. The following is the conservation equation for all liquid phases:

$$
\frac{\partial}{\partial t}\left(\rho Y_{i}\right)+\nabla \cdot\left(\rho \vec{v} Y_{i}\right)=-\nabla \cdot \vec{J}_{j}
$$

Hence, sulfur is one of the constituents of microalloyed steel and one objective of this work is to understand the motion of alumina inclusions under interfacial tension. In this context, sulfur is diffused in steel and, thus, the diffusion coefficient can be determined by the following equation [40]:

$$
D=\frac{k T}{2 \pi \mu d}\left[\frac{m_{1}+m_{2}}{2 m_{2}}\right]^{\frac{1}{2}}
$$

where $d$ is the diameter of atoms, $m_{1}$ and $m_{2}$ are the atomic mass of solute and solvent, respectively. $T$ is the temperature of the melt, $\mu$ is the viscosity of the molten metal and $k$ is Boltzmann's constant $\left(1.38 \times 10^{-23} \mathrm{~J} / \mathrm{K}\right)$.

The volume of fluid (VOF) model is used for multiphase computations with precisely specified immiscible incompressible fluid interfaces. Molten steel and alumina inclusions were used as two immiscible fluids in this study. Pressure and velocity are factors that are shared by all processes and correspond to volume-averaged values. The mathematical equations were directly volume-averaged to produce a single set of equations, and the fluid interface was monitored using the color function $\Psi$, which is defined as follows. When the value of $\Psi=1$, the control volume is assumed to be filled only with the first phase. In contrast, when $\Psi=0$, the control volume is assumed to be filled by the second phase. However, when the condition of $0<\Psi<1$ is met, then it is considered that the element has an interface, and it separates into two different phases. Further, in a numerical solution, the fluid front is calculated by solving the following transport equation:

$$
\frac{\partial F}{\partial t}+u \cdot \nabla F=0
$$

Here, $F$ is the volume fraction of the fluid in a cell and $u$ is the flow velocity vector.

Geo-reconstruct advection schemes were used in this research. The discretization process of governing equations is well known to have a major impact on device representation. As a result, the explicit scheme with the geo-reconstruct interface interpolation scheme yielded the solution to the two-dimensional problem. Normal finite-difference 
interpolation schemes are extended to the volume fraction values computed at the previous time point in the explicit method.

$$
\frac{\alpha_{q}^{n+1} \rho_{q}^{n+1}-\alpha_{q}^{n} \rho_{q}^{n+1}}{\Delta t} V+\sum_{f}\left(\rho_{q} U_{f}^{n} \alpha_{q, f}^{n}\right)==\left[\sum_{p=1}^{n}\left(\dot{\mathrm{m}}_{p q}-\dot{\mathrm{m}}_{q p}\right)+S_{\alpha_{q}}\right] V
$$

\subsection{Numerical Details}

In the present work, inclusion particle distribution during AC flash welding has been simulated using a two-dimensional multiphase CFD model. In addition to this, a dynamic mesh along with discrete phase models from Ansys Fluent (Academic version: 18.0, ANSYS, Inc., Canonsburg, PA, USA) have been applied to mimic the steel plate motion in the simulation. The fluid flow was expected to be laminar and the aspect ratio of the domain significant, hence the two-dimensional domain can give significant accuracy to the results. Initially, we investigated the inclusion motion during the upsetting process of steel plates. In the upsetting process, steel plates are pushed toward each other by a significant force. The weld pool temperature plays an important role in the displacement of inclusion particles, hence we studied inclusion distribution at different weld pool temperatures. Further, we also studied inclusion motion behavior and distribution due to their size. In this work, we have assumed a spherical shape of inclusion particles and neglected the conglomeration phenomenon of inclusion particles. The volume of fluid (VOF) method was selected for multiphase simulation and a further species model was used to create surfactant concentration (sulfur in this study). The temperature gradient and sulfur concentration affect the interfacial tension build-up between alumina inclusions and molten metal. For the simplification of problem, the whole melt flow was assumed to be a laminar flow due to the actual size of the domain and viscosity of molten steel. The radiation from molten metal was also ignored and an absolute heat transfer coefficient was considered at the molten metal and air interface. Furthermore, a constant initial temperature of the domain was considered for the simplification. Figure 2 illustrates a schematic diagram of the domain, details of the phases and meshed zone along with dimensions. The outer sidewalls of the domain (heat transfer coefficient $0.85 \mathrm{w} / \mathrm{m}^{2} \cdot \mathrm{k}$ ) were considered as rigid walls and the weld pool was considered as a dynamic mesh zone (deforming body) in the CFD model. The thermo-mechanical properties for the simulation were obtained from the previous work of Siddiqui et al. [26]. The outer walls of the domain were considered as convective boundaries with proper heat transfer coefficients. The steel plates (left- and right-side walls in the domain) were supplied with suitable thermal conductivity of the steel alloy. The other walls of the domain exposed to air, as shown in Figure 2, were considered as a pressure inlet and outlet. Initially, 10,000 elements were used to calculate the solution. Further, 17,000 and 25,000 elements were checked to calculate mean velocity at the mid-vertical plane of the domain. The grid independency test suggested that the change in mean velocity at the mid-vertical plane of the domain did not change more than 2.12 percent. However, increasing the number of elements showed a significant rise in computation time and also created a stability issue in the dynamic mesh solution. The complete domain consisted of around 17,000 tetrahedral elements. Tetrahedra cells are not suitable for dynamic mesh modeling in Ansys Fluent. Further, the maximum element size was 30 microns in the abovementioned domain. The convergence of the solution was studied by measuring the average temperature at the mid-vertical plane of the domain. The thermo-physical properties of molten steel and alumina inclusions were obtained from [26]. The surface tension correlation between molten steel and air was used in the simulation by using Equation (1). Further, Equation (2) was utilized in a numerical model to quantify the interfacial tension between molten steel and alumina inclusions. 


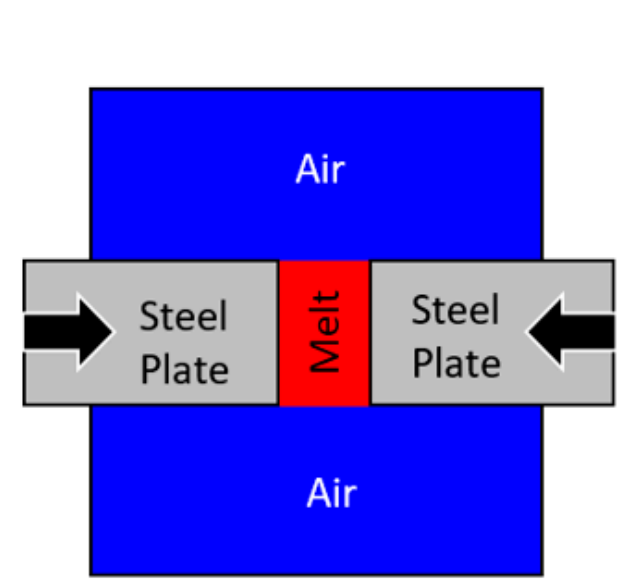

(a)

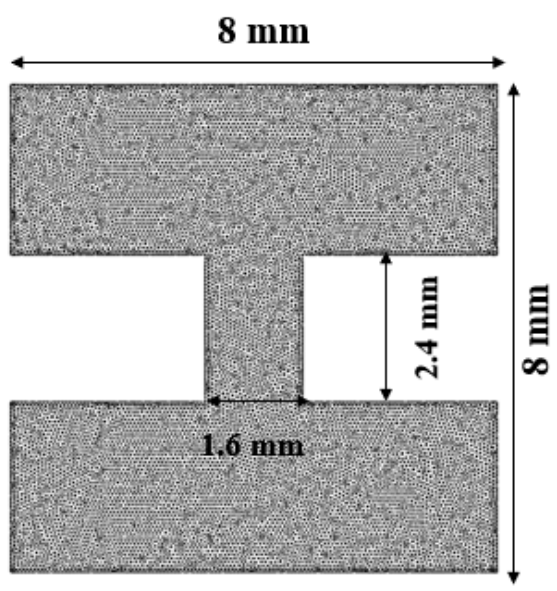

(b)

Figure 2. (a) Schematic of domain, (b) domain meshing.

In the second phase of numerical modeling, we studied the inclusion particle's movement near the solidifying molten steel boundary. The interfacial tension on inclusion particles, in other words, Marangoni forces, is dependent upon surfactant concentration and temperature. In our study, we have selected sulfur as a surfactant to understand the behavior of inclusion particles at solidifying metal boundaries. In the second phase, we considered a microscale of the welded domain. Figure 2 illustrates the domain considered for the study of an inclusion particle's motion behavior during solidification. The inclusion particles may be pushed and engulfed in solidifying boundaries due to the change in interfacial tension.

A two-phase numerical model, i.e., molten steel and alumina inclusions, was considered for the simulation. The species model was utilized to achieve the sulfur concentration throughout the domain. Further, the solidification model was also considered in this numerical model. Both phases of the simulation were transient in nature and the species continuity equation was solved at each time step. A general model for a welding simulation was validated with the experimental results of Sadeghian et al. [41]. The experimental temperature profile was compared with predicted numerical results. The predicted results seem to have good agreement with the experimental data.

\section{Results and Discussion}

\subsection{Upsetting Process}

In the first phase of the numerical investigation, we studied the effect of upsetting rate, inclusion diameters and temperature on the inclusion particle distribution. Initially, we considered three different upsetting rates for the AC flash welding procedure. During the upsetting procedure, plates were pushed at three different velocities, i.e., $19.3 \mathrm{~m} / \mathrm{s}$, $15.5 \mathrm{~m} / \mathrm{s}$ and $12.8 \mathrm{~m} / \mathrm{s}$.

In Figure 3, it can be seen here that inclusion particles are moving because of the motion of the plates. In this work, three different cases of velocity were studied. In the first case, the velocity is $19.3 \mathrm{~m}$ per second which is the highest one and we can see here that inclusion particles are moving rapidly in the outward direction. For the second case, we can see here that the movement of particles is not as rapid as in the case of the previous one. In the 3rd case, where the velocity was slower, it can be seen that particles are settled in a welded joint. Hence, we can say that the high upsetting rate affects the motion. In other words, inclusion motions were affected by the upsetting rate and it is expected that inclusions are forced in an outward direction. In flash butt welding, the upsetting rate is critical. Three cases of unsettling rate, $19.3 \mathrm{~m} / \mathrm{s}, 15.57 \mathrm{~m} / \mathrm{s}$ and $12.82 \mathrm{~m} / \mathrm{s}$, have been investigated in this study. The higher upsetting rate necessitates a greater force to pass through the plates, which affects the weld pool's flow dynamics. In comparison to the 
lower upsetting average, the high upsetting rate washed out most of the alumina inclusion particles from the weld joint. Figure 3 depicts the expected passage of inclusion particles at various upsetting rates. When a strong force is applied to the weld region, alumina particles are displaced from the weld zone.

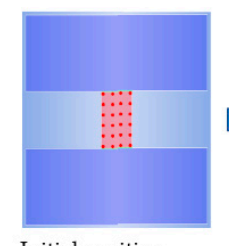

Initial position of Particles. $(t=0 \mathrm{~s})$
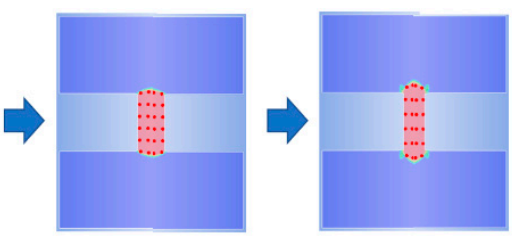

.

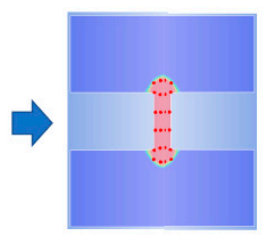

Final position of Particles. $(t=0.13 \mathrm{~s})$

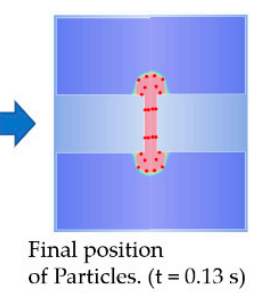

Figure 3. The distribution of inclusions during upsetting operation.

It should be remembered that as the unsettling rate increases, the average velocity of inclusion particles increases. Additionally, a higher upsetting intensity improves the separation of alumina inclusions from the weld region. In the case of a low upsetting rate, a higher particle density can be found near the middle of the welding region. When a higher upsetting rate is used, however, a higher concentration of inclusions can be seen on the outside of the weld joint.

Figure 4 shows the instantaneous velocity distribution of inclusion particles during the upsetting process $(19.3 \mathrm{~m} / \mathrm{s})$. The velocity distribution illustrates the movement and velocity of increased particles at different time steps. The plot was created from a set of inclusion particles whose motion was traced. Here, we can see that each inclusion particle has a different motion at a specific time. It also shows that various particles have a different velocity at any corresponding time step. Figure 5 shows the inclusion removal percentage with respect to upsetting velocity. A higher percentage of inclusion particles have were removed from the welded joint zone due to the high upsetting rate. It can be noted that around $96 \%$ of inclusion particles were moved out of the main joint area when the upsetting rate was $19.2 \mathrm{~m} / \mathrm{s}$. In the second case, around $91 \%$ of inclusion particles were removed. In the third case, $87 \%$ of inclusion particles were removed from the welded zone at a $12.8 \mathrm{~m} / \mathrm{s}$ upsetting rate.

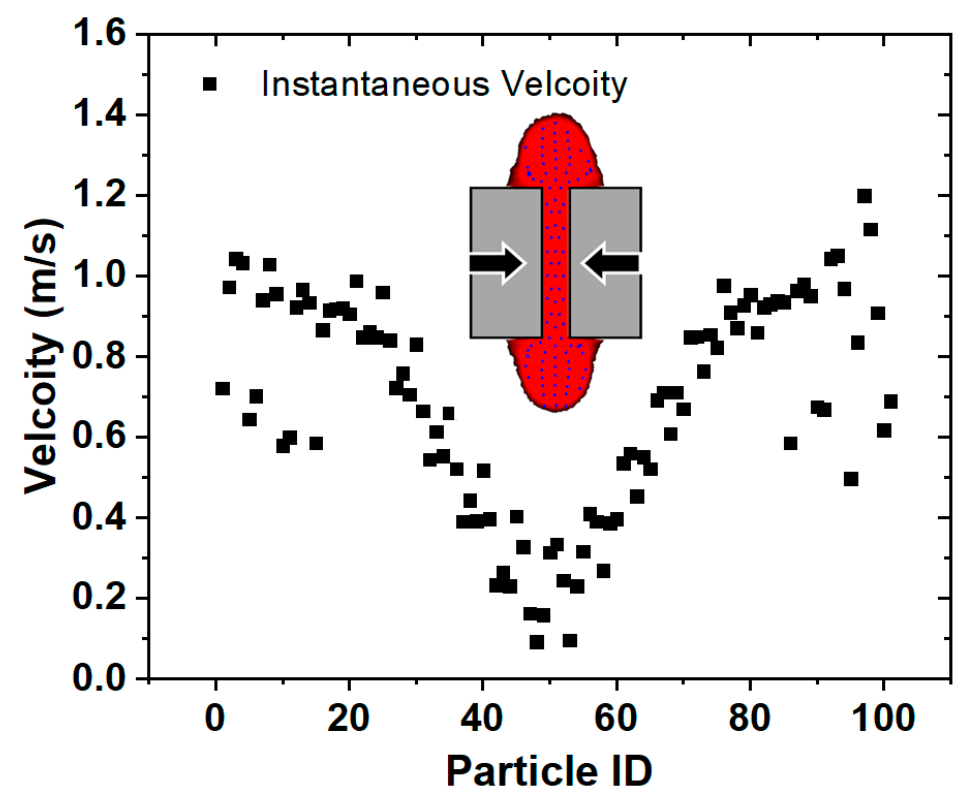

Figure 4. Instantaneous velocities of inclusion particles (upsetting rate: $19.3 \mathrm{~m} / \mathrm{s}$ ). 


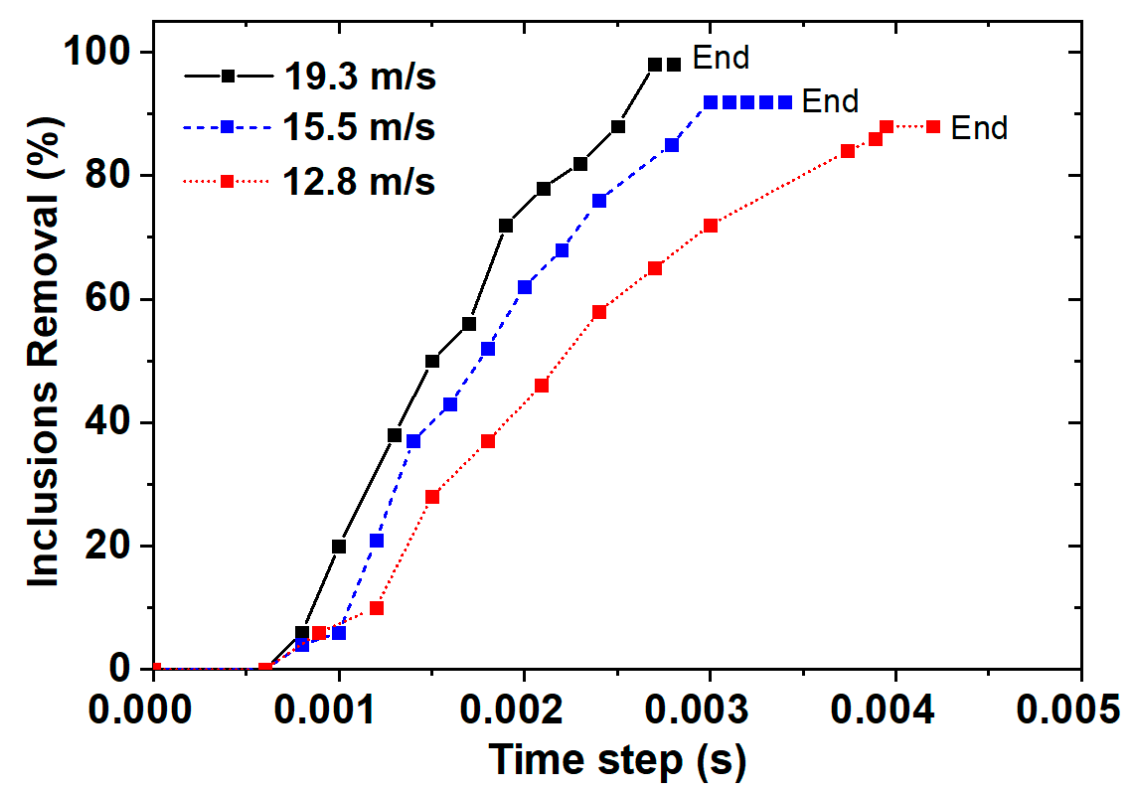

Figure 5. Predicted velocities of inclusion particles during upsetting operation.

\subsection{Inclusion Size}

The impact of inclusion diameter has been investigated in this research work. The different inclusion sizes have been investigated to understand the inclusion motion behavior during the upsetting process when the molten weld pool is squeezed with a high upsetting rate. For simplicity of problem formulation, we have assumed spherical shapes of inclusion particles. The inclusion particle diameters in this analysis were 5, 100, 200, 400 and 500 micrometers. In this case, we have considered a fixed upsetting rate of $15.5 \mathrm{~m} / \mathrm{s}$. A certain set of inclusions based on diameter sizes was introduced in the domain and the further effect of upsetting rates was studied. Figure 6 shows the average velocities of inclusion particles with respect to their sizes. It is evident from the plot that the average velocities of inclusion particles are higher for the larger inclusions. However, the average velocities of inclusion particles are marginally affected by size. Hence, inclusion motion behavior is affected when the diameter of particles is larger than 400 micrometers. It is observed that the average velocities of particles remain the same around the initial and final condition of the upsetting rate. Further, inclusion particles of a larger size (400 and 500 micrometers) have higher average velocities from $0.0020 \mathrm{~s}$ to $0.0025 \mathrm{~s}$. The flash welding process is very quick and the distance between two adjoining plates remains at a few hundred micrometers. It is also expected that the huge force exerted during the upsetting process causes the weld pool to flow in an outward direction and, subsequently, a larger inclusion attains higher momentum energy. Moreover, the motion of inclusion particles can be correlated from the data of Figure 4, where the instantaneous velocity of particles is shown. It shows that the location of particles affects the instantaneous velocity in the weld zone and this plays a vital role in the removal process. 


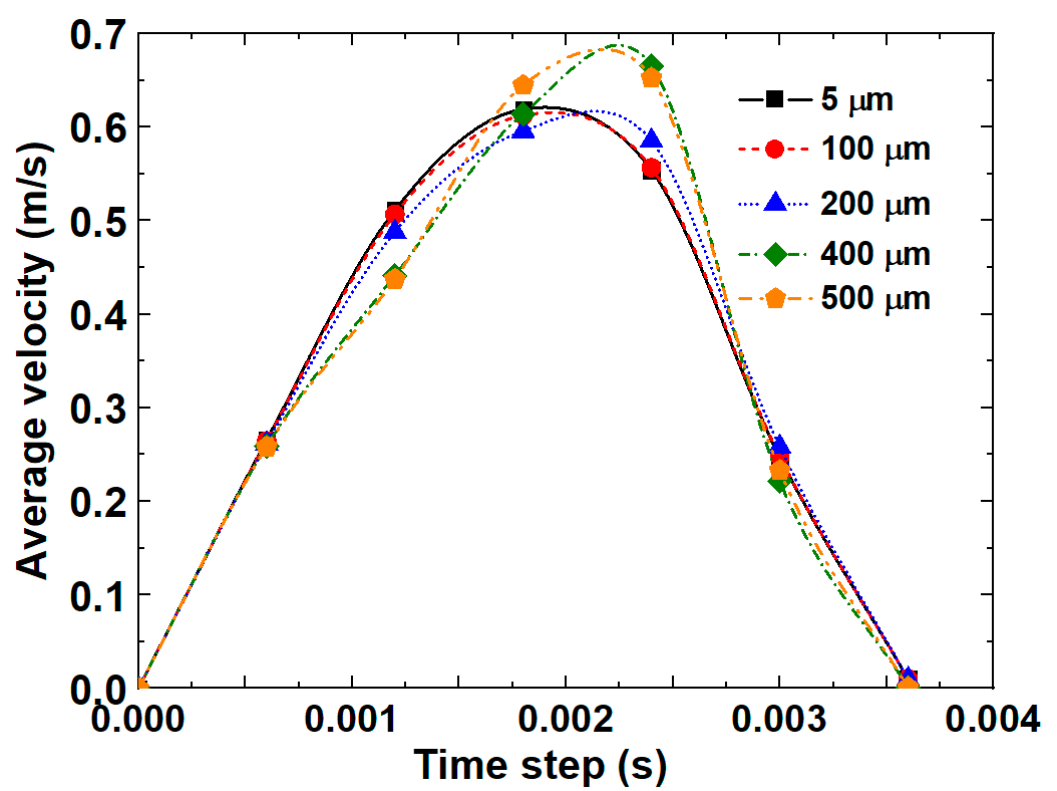

Figure 6. Plot of average velocities during the upsetting process.

\subsection{Solidification}

The initial weld pool temperature formed due to arc flash was considered to be $2000 \mathrm{~K}$ in this research work. The solidification of the weld pool was rapid due the smaller size of the contact area of the two adjoining plates of metal and, further, the high conductivity of the steel material. Figure 7 shows the solidification process of the weld zone. The temperature contour is shown from $1808 \mathrm{~K}$ to $1781 \mathrm{~K}$, and at this temperature liquid metal changes into the solidus phase. The solidification process contours are shown to emphasize the rapid transformation of the liquid phase into the solidus phase during the arc welding process when the contact area is small. More details on the role of flash temperature have been discussed by Siddiqui et al. [26].

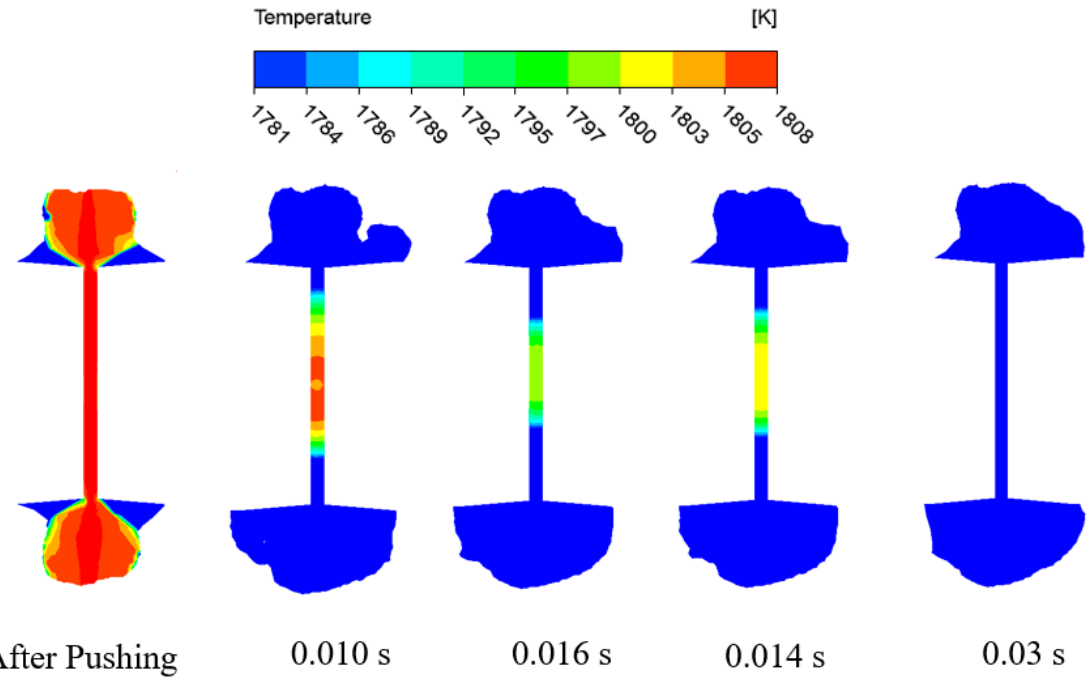

Figure 7. Solidification contour of welded joint after upsetting process.

\subsection{Pushing and Engulfment of Inclusions}

The distribution of alumina inclusion particles trapped in the welded zone is also influenced by the interfacial tension and subsequently the Marangoni force, which is also known as the pushing and engulfment phenomenon. The temperature and surfactant concentration in the liquid weld pool are variables that affect the interfacial tension. Further, 
pushing and engulfment of inclusion particles near the solidifying interface are related to interfacial properties. When the gradient of the interfacial tension exists around an inclusion, then inclusion particles move from a position with higher interfacial tension to other positions with lower interfacial tension. Figure 8 represents the effect of the Marangoni force on inclusions at the solid/liquid interface. In general, the surface tension decreases with increasing temperature as is the case for pure metals. However, this is not always the case when an alloy contains a surface-active element. The concentration of minor elements in steels is significant for controlling the Marangoni convection in the molten metal, and the consecutive solidification in a mold.

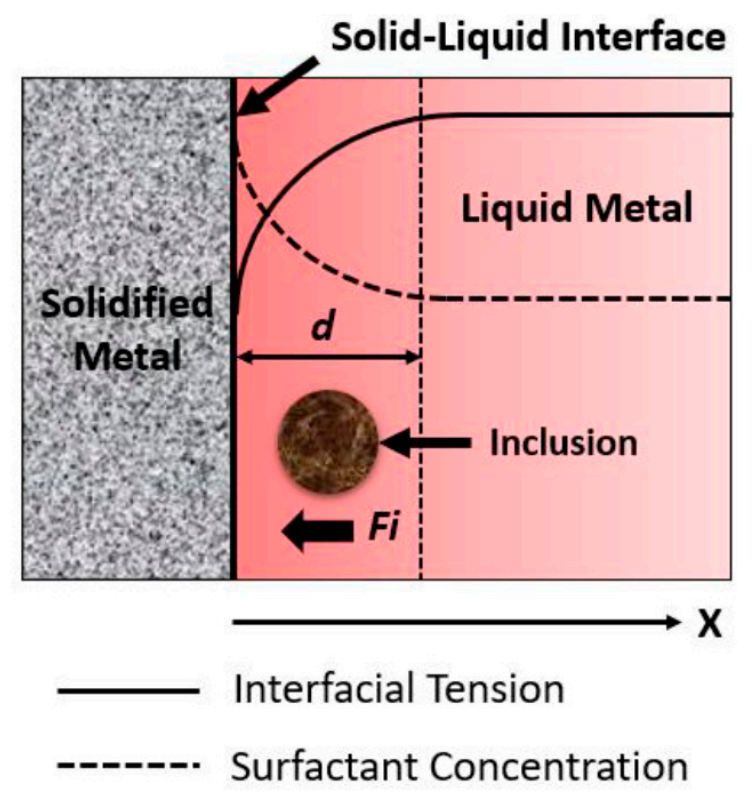

Figure 8. The effect of Marangoni force on an inclusion near the solidifying front.

We have studied the motion behavior of alumina inclusions at the solidifying boundary of the weld pool. We have also studied the effect of surfactant concentration on the pushing and engulfing phenomenon of alumina inclusions. The SPFH590 microalloyed steel also contains sulfur as microconstituents. Hence, in this simulation work, we have considered sulfur as a surfactant and, further, the effect of sulfur concentration on the pushing and engulfment phenomenon of inclusion particles at the solidifying interface has been studied.

A new two-dimensional numerical model was developed to simplify and precisely study inclusion motion at the solidifying interface. In this model, we have neglected the dynamic mesh model and only considered a domain with molten metal along with proper heat transfer boundary conditions. The size of the domain was $2.4 \mathrm{~mm}$ in length and $0.1 \mathrm{~mm}$ in width. A certain number of alumina inclusions particles (20-micrometer diameter) were distributed along the length of the domain at random locations. The boundary conditions of the domain are shown in Figure 9. The radiative and conductive boundary conditions were placed at the horizontal interface while the vertical sides had conductive boundary conditions. The simulation studies were carried out with two different sulfur concentrations, i.e., $10 \mathrm{ppm}$ and $64 \mathrm{ppm}$. The interfacial tension relationship varies significantly around these two values [42]. At the start of the simulation, the weld pool was considered in the liquid phase at a temperature of $1808 \mathrm{~K}$ and solidification calculation started with respect to the given time steps. Figure 10a,b shows the instantaneous solidification contour of the weld pool and the location of alumina inclusions. Figure 10a shows the solidification of the weld pool and motion of alumina inclusions under the Marangoni force when the sulfur concentration is $10 \mathrm{ppm}$. It can be noted that the solidus phase is rapidly achieved within a fraction of a second. The other important aspect of this study is to find the exact displacement of alumina inclusions due to the interfacial gradient raised during solidification Figure 10b also shows a similar phenomenon of flash weld pool solidification but at a 
sulfur concentration of $64 \mathrm{ppm}$. A careful study of Figure 11 shows that inclusions have been displaced. At both sulfur concentrations, the solidification phenomenon is the same, but inclusion displacement is affected by surfactant concentration. Careful observation of Figure 10b suggests that inclusion displacement is negligible. Both figures give a clear idea of solidification, but the inclusions' pushing and engulfment phenomenon is not clear due to the rapid solidification and size of the domain. Thus, we studied this phenomenon further with an effectively small domain size with a slower solidification rate to see the effect of surfactant concentration.

A new smaller domain was selected for CFD simulation based on the previous model, as shown in Figure 12. This domain has a length of 200 microns in the vertical direction and a width of 100 microns in the horizontal direction. The size of each element in this domain is in the order of 1 micron. The boundary conditions of this domain have been slightly modified to simplify the solution and effectively capture the inclusion motions at the solidifying front due to the Marangoni force. In this work, the upper horizontal wall of the domain was considered as a convective boundary. The other three boundaries of the domain were considered adiabatic walls. The selected boundary conditions were helpful to effectively define the inclusions' pushing and engulfment at the solidifying boundary in the vertical direction.

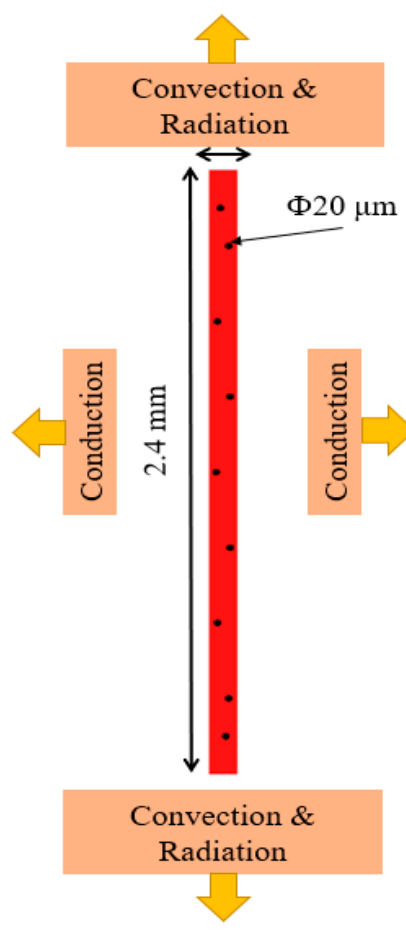

Figure 9. Geometric domain considered for simulation. 


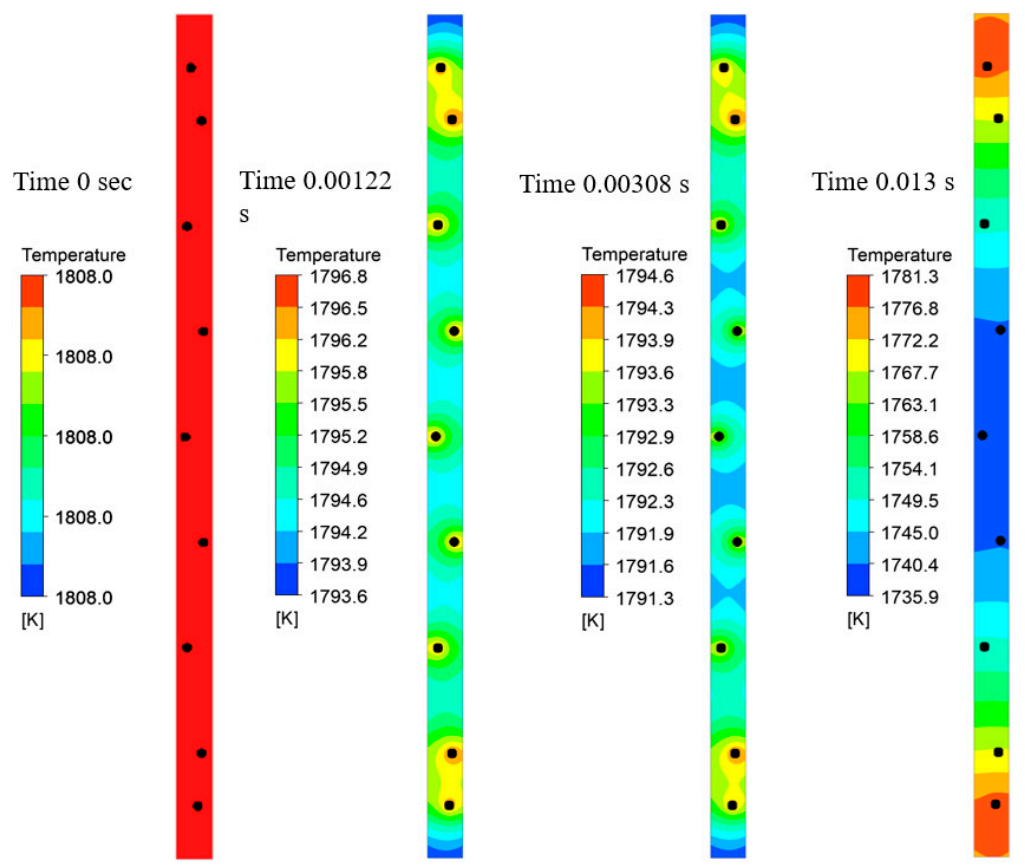

(a)

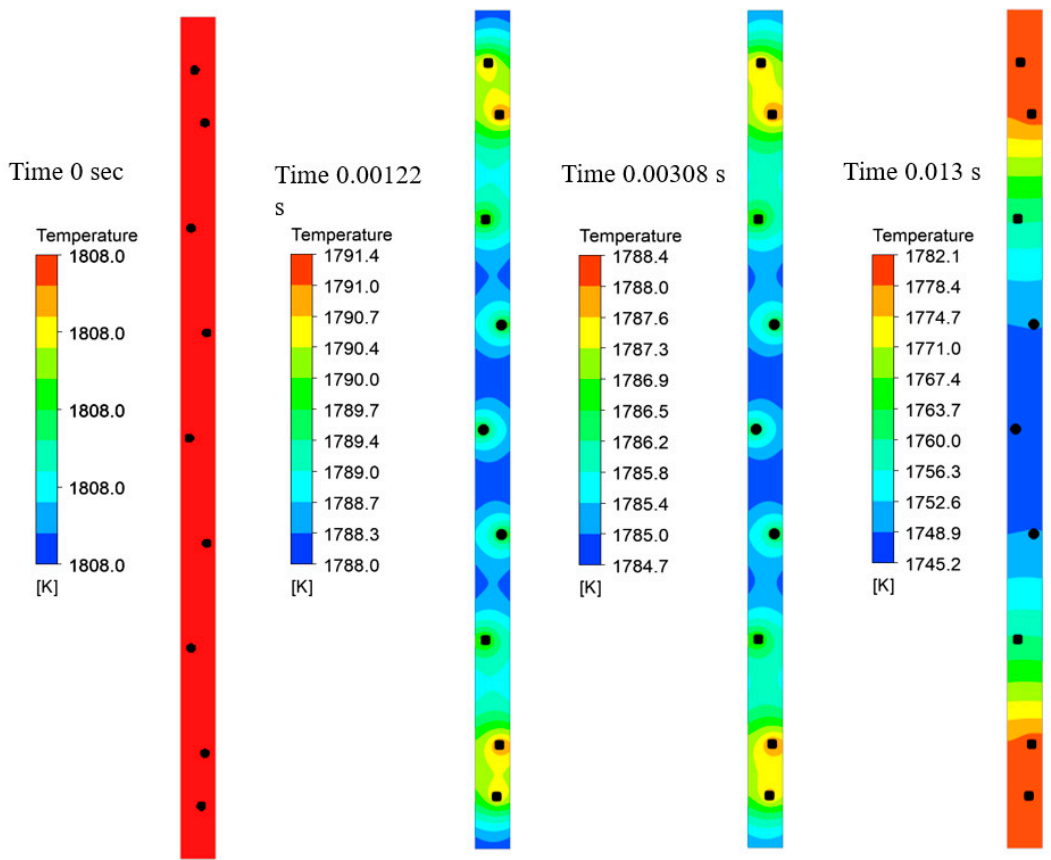

(b)

Figure 10. (a) Temperature profile and inclusion motion at $10 \mathrm{ppm}$ sulfur concentration, (b) temperature profile and inclusion motion at $64 \mathrm{ppm}$ sulfur concentration. 

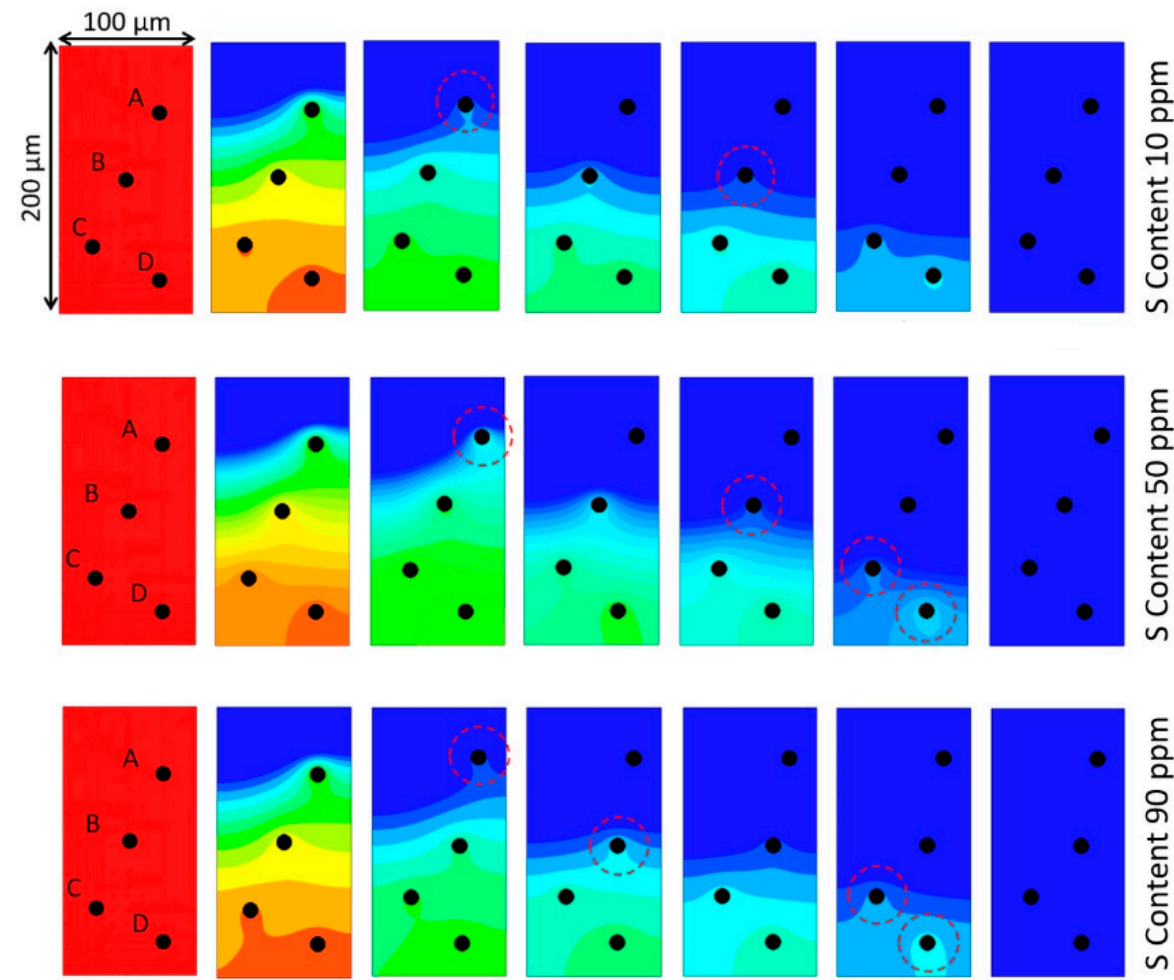

Temperature

$[\mathrm{K}]$

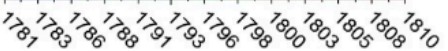

Figure 11. Pushing and engulfment of alumina inclusion particles during solidification of the weld pool.

\section{Initial Position of Inclusion Final Position of Inclusion}

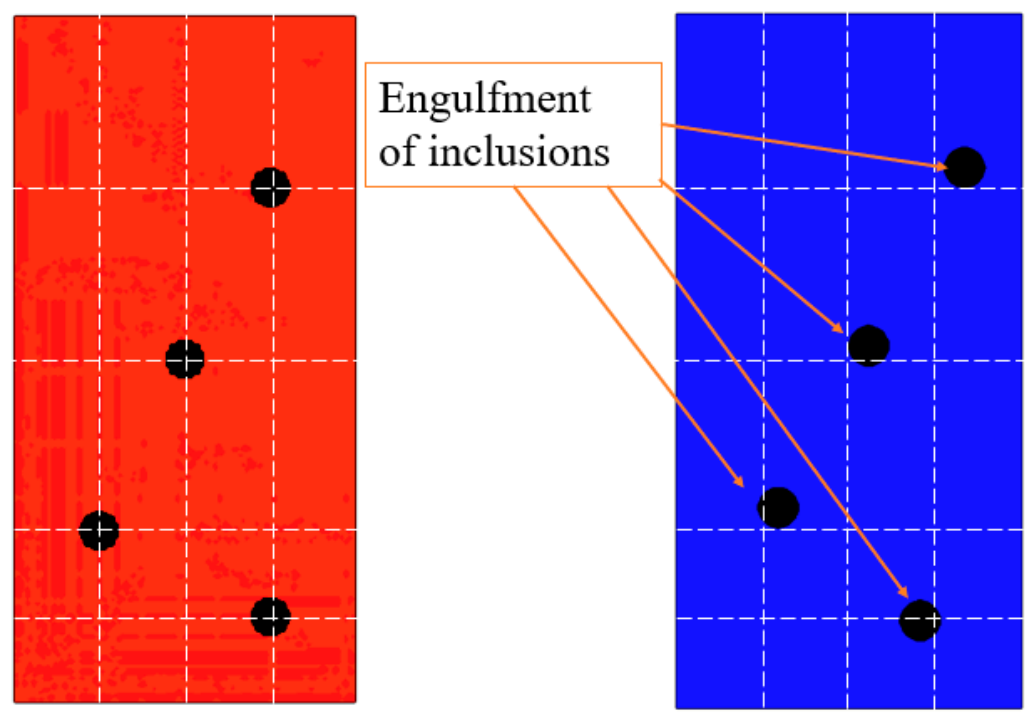

Figure 12. Engulfment of inclusion particles during solidification (S: $10 \mathrm{ppm}$ ).

As the temperature of the cell reaches the solidus temperature $(1781 \mathrm{~K})$, the alumina inclusions' velocities are expected to cease. Figure 11 depicts the pushing and engulfment of inclusions during the solidification period. The figure depicts an instantaneous snapshot of inclusion displacement with respect to sulfur concentration. The temperature of the cells is represented by the colored band. The solidus temperature contour line is depicted by the 
blue band. The interfacial tension formed between the molten steel and alumina process affects inclusion particles. It can be noted from Figure 11 that alumina inclusions are engulfed by the solidifying interface due to interfacial tension developed by the addition of sulfur. However, the sulfur concentration plays an important role in the development of interfacial tension. The interfacial tension decreases slightly with the addition of sulfur at $64 \mathrm{ppm}$ and further increases with the addition of more sulfur [42]. Further, simulation results also show that particles are forced into the molten region when the sulfur content is between 10 and $90 \mathrm{ppm}$. This clearly shows that the solid-liquid propagating front engulfs alumina inclusions. The simulation findings show that interfacial tension force caused by sulfur concentration and temperature gradient affects alumina inclusions in weld pools. Due to the rapid solidification of the weld pool, the motion activity of the alumina inclusions was only registered for a few seconds. Figure 12 shows the engulfment of alumina inclusions in the solidifying interface when the sulfur concentration is $10 \mathrm{ppm}$. In Figure 11 it can be observed that the inclusion particles are pulled by the solid-liquid interface in the case of $10 \mathrm{ppm}$. As the solidification front advances, more inclusion particles were pulled by the solid-liquid front. However, this phenomenon is not visible in the case of $50 \mathrm{ppm}$ of sulfur due to a decrease in interfacial tension. In the case of $90 \mathrm{ppm}$ of sulfur, interfacial tension increases, which is evident from the experiment on the relation and, subsequently, alumina inclusions are engulfed.

Further, the motion of individual alumina inclusions is shown during the solidification of the weld pool in Figure 13. On the other hand, sulfur (20 ppm) in terms of mass fraction is shown in Figure 14 during the weld pool solidification. The sulfur concentration contours have been illustrated up to the solidus temperature. It is visible that alumina inclusions are engulfed in the solidifying interface due to Marangoni forces since this simulation considers a microgravity environment. In addition to this, the mass fraction of sulfur was assumed to be homogenous during the initial conditions. However, sulfur segregates at the solidifying front during weld pool solidification, as shown by the predicted contours in Figure 14.

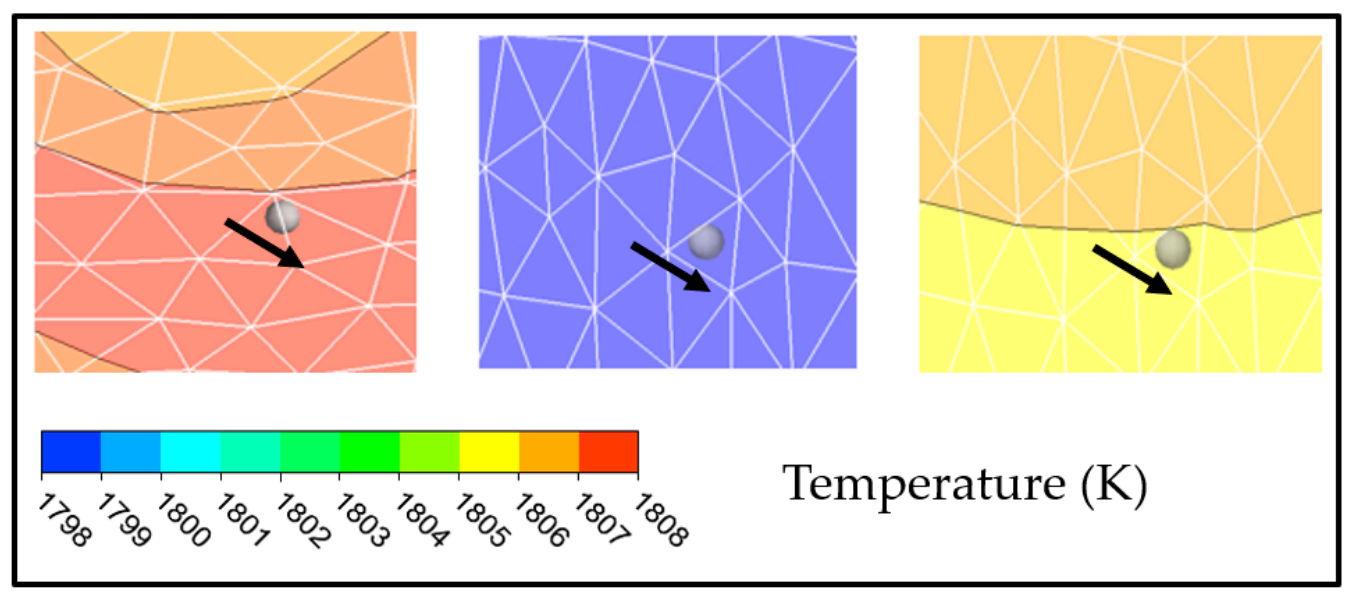

Figure 13. Inclusion motion during solidification due to Marangoni force. 


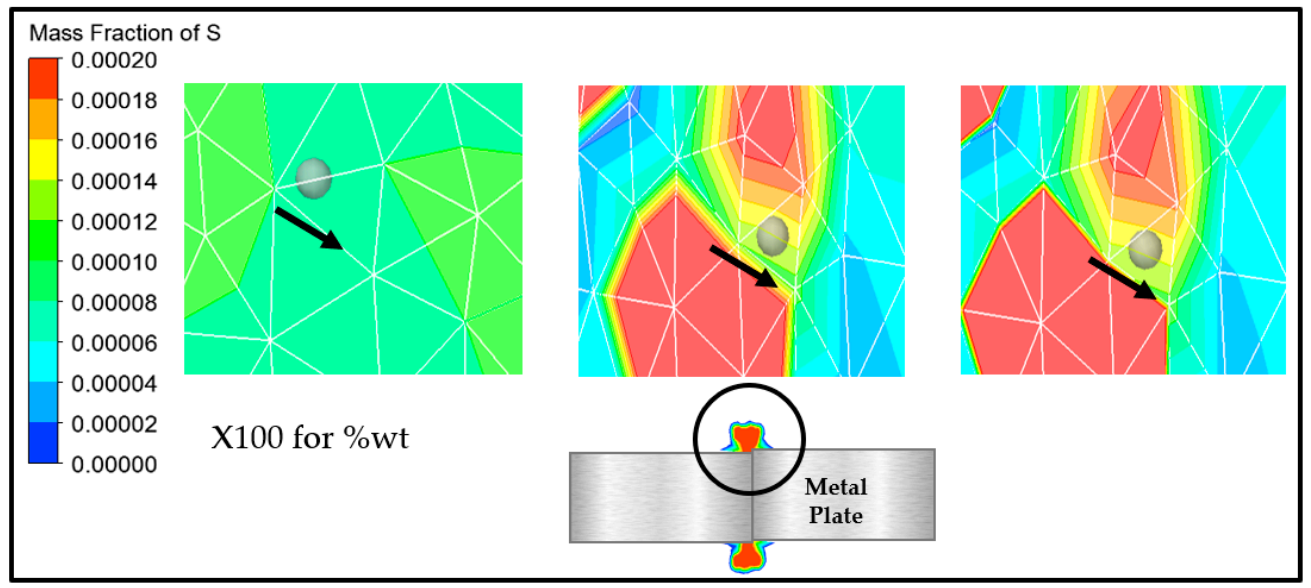

Figure 14. Mass fraction of sulfur during solidification process.

\section{Conclusions}

The numerical model was developed to study alumina inclusion motion behavior in an AC flash welding process. The two-dimensional, multiphase CFD-based model included a dynamic mesh model which created a very realistic prediction of weld pool flow during the upsetting process. The numerical model also included alumina inclusions which were solved by the discrete phase method and specific correlations of interfacial tensions among SPH50 steel, alumina inclusions and air. The species model was opted for, providing a homogenous concentration of sulfur in the domain. Further, the solidification of weld pool liquid steel has been solved by the enthalpy-porosity method. Moreover, several different types and sizes of the domain have been used to study certain kinds of inclusion motion behavior of alumina in this work. In general, non-metallic inclusions are expected to move in the weld pool in two ways: by upsetting the motion of plates and secondly by interfacial forces generated during solidification. The latter method of inclusion motion is called the pushing and engulfment phenomenon of particles under Marangoni forces. Initially, a dynamic mesh-based CFD model was developed along with the abovementioned models to investigate the upsetting process and effect of other parameters. In addition to this, more specific domains and models have been selected in this work to precisely study the inclusion motion behavior under the influence of interfacial tension.

The simulation findings indicate that both the upsetting procedure and the size of the inclusion have a significant effect on the distribution of inclusions. The inclusions are pushed away from the welded region towards the outer weld surface by molten metal forced during the upsetting process. It was seen that inclusion particles were pushed by the motion of the liquid metal. The force exerted by the plate movement affected the movement of the liquid pool of the weld zone. It has also been seen that some inclusion particles were found in the middle zone of the weld. Hence, we can say that the initial movement of inclusion particles during the upsetting process is significantly affected by the liquid metal pool motion. When the diameter of inclusion particles was increased, a similar result was observed. In practice, however, the initial flash temperature affects weld consistency and inclusion pollution. It has been seen from the experiment and the numerical results that inclusion movement is dependent upon various factors. Firstly, the upsetting rate, temperature and inclusion diameter play an important role. Further, we have seen that surfactant concentration is very important. The surfactant concentration affects the inclusion motion behavior. Moreover, surfactant concentration affects the interfacial tension and, subsequently, inclusion particles are affected by Marangoni forces. From the present work, we have seen that the inclusion particle's motion behavior was significantly affected by surface tension. In this work, it was noted that the sulfur concentration in microalloyed steel affected the inclusion motion at the solid-liquid interface. It was also noted that inclusion particles were pushed and engulfed by the moving solid interface. The findings are solely concerned with the distribution of alumina inclusions that were 
already present in the weld pool under the conditions described. To specifically evaluate the motion activity of alumina particles at the solid-liquid interface of the weld pool under the effect of interfacial stress, a computational investigation was carried out. The sulfur concentration and temperature differential caused the Marangoni force in the welding zone. Under the effect of a higher surface tension gradient between inclusions and melt, the predicted findings show that inclusions were vulnerable to engulfment by the solidification front. A rise in sulfur content (to $100 \mathrm{ppm}$ ) had no discernible effect. Despite this, due to the rapid solidification rate, the displacement of inclusions under the influence of surface tension gradient was minimal.

Author Contributions: Conceptualization, M.I.H.S.; methodology, M.I.H.S., H.A. and J.O.; software, M.I.H.S.; validation, M.I.H.S. and M.A.A.; formal analysis, D.D.; investigation, M.I.H.S.; resources, M.I.H.S., H.A. and J.O.; writing—original draft preparation, M.I.H.S. and M.A.A.; writing—review and editing, M.I.H.S., H.A., J.O. and D.D.; funding acquisition, D.D. All authors have read and agreed to the published version of the manuscript.

Funding: This research was funded by Lucian Blaga University of Sibiu \& Hasso Plattner Foundation, grant number LBUS-IRG-2020-06.

Data Availability Statement: Data presented in this article are available at request from the corresponding author.

Acknowledgments: Project financed by Lucian Blaga University of Sibiu \& Hasso Plattner Foundation research grants LBUS-IRG-2020-06.

Conflicts of Interest: The authors declare no conflict of interest.

\section{References}

1. Kim, D.C.; So, W.J.; Kang, M.J. Effect of flash butt welding parameters on weld quality of mooring chain. Arch. Mater. Sci. Eng. 2009, 38, 112-117.

2. Wang, W.; Shi, Y.; Lei, Y.; Tian, Z. FEM simulation on microstructure of DC flash butt welding for an ultra-fine grain steel. J. Mater. Process. Technol. 2005, 161, 497-503. [CrossRef]

3. Ichiyama, Y.; Kodama, S. Flash-butt welding of high strength steels. Nippon Steel Tech. 2007, 95, 81-87.

4. Turner, R.P.; Perumal, B.; Lu, Y.; Ward, R.M.; Basoalto, H.C.; Brooks, J.W. Modeling of the Heat-Affected and Thermomechanically Affected Zones in a Ti-6Al-4V Inertia Friction Weld. Metall. Mater. Trans. B 2019, 50, 1000-1011. [CrossRef]

5. Kitano, H. Numeric Law Discovery and Knowledge Extraction from Welding Phenomena Using Machine Learning Technique. Mater. Jpn. 2019, 58, 449-452. [CrossRef]

6. Chen, Z.; Nash, P.; Zhang, Y. Correlation of Cooling Rate, Microstructure and Hardness of S34MnV Steel. Metall. Mater. Trans. B 2019, 50, 1718-1728. [CrossRef]

7. Šebestová, H.; Horník, P.; Mrňa, L.; Doležal, P.; Mikmeková, E. The Effect of Arc Current on Microstructure and Mechanical Properties of Hybrid LasTIG Welds of High-Strength Low-Alloy Steels. Metall. Mater. Trans. B 2018, 49, 3559-3569. [CrossRef]

8. Matsui, Y.; Iizuka, Y.; Okabe, T.; Inoue, T. Evaluation method for low temperature toughness of weld seam of HFW pipe based on the distribution of scattered type penetrator. ISIJ Int. 2017, 57, 2010-2015. [CrossRef]

9. Barrick, E.J.; DuPont, J.N. Mechanical properties and microstructural characterization of simulated heat-affected zones in $10 \mathrm{wt}$ pct Ni steel. Mater. Sci. Eng. A 2019, 748, 189-204. [CrossRef]

10. Moeini, G.; Ramazani, A.; Hildebrand, J.; Roessler, C.; Koenke, C. Study of the effect of microstructural variation on the low cycle fatigue behavior of laser welded DP600 steel: Simulation and experimental validation. Mater. Sci. Eng. A 2018, 730, 232-243. [CrossRef]

11. Çetinkaya, C.; Arabaci, U. Flash butt welding application on $16 \mathrm{MnCr} 5$ chain steel and investigations of mechanical properties. Mater. Des. 2006, 27, 1187-1195. [CrossRef]

12. Bhattacharyya, S.; Adhikary, M.; Das, M.B.; Sarkar, S. Failure analysis of cracking in wheel rims-Material and manufacturing aspects. Eng. Fail. Anal. 2008, 15, 547-554. [CrossRef]

13. Lina, S.; Deng, Y.-L.; Tanga, J.-G.; Deng, S.-H.; Linc, H.-Q.; Ye, L.-Y.; Zhang, X.-M. Microstructures and fatigue behavior of metal-inert-gas-welded joints for extruded Al-Mg-Si alloy. Mater. Sci. Eng. A 2019, 745, 63-73. [CrossRef]

14. Lu, P.; Xu, Z.; Jiang, K.; Ma, F.; Shu, Y. Influence of flash butt welding parameters on microstructure and mechanical properties of HSLA 590CL welded joints in wheel rims. J. Mater. Res. 2017, 32, 831-842. [CrossRef]

15. Shajan, N.; Arora, K.S.; Sharma, V.; Shome, M. Effect of upset pressure on texture evolution and its correlation to toughness in flash butt joints. Sci. Technol. Weld. Join. 2018, 23, 434-440. [CrossRef]

16. Shajan, N.; Arora, K.S.; Asati, B.; Sharma, V.; Shome, M. Effects of Post-Weld Heat Treatment on the Microstructure and Toughness of Flash Butt Welded High-Strength Low-Alloy Steel. Metall. Mater. Trans. A 2018, 49, 1276-1286. [CrossRef] 
17. Joo, M.S.; Noh, K.-M.; Kim, W.-K.; Bae, J.-H.; Lee, C.-S. A Study of Metallurgical Factors for Defect Formation in Electric Resistance Welded API Steel Pipes. Metall. Mater. Trans. E 2015, 2, 119-130. [CrossRef]

18. Yu, X.; Feng, L.; Qin, S.; Zhang, Y.; He, Y. Fracture analysis of U71Mn rail flash-butt welding joint. Case Stud. Eng. Fail. Anal. 2015, 4, 20-25. [CrossRef]

19. Ichiyama, Y.; Saito, T. Factors affecting flash weldability in high strength steel-A study on toughness improvement of flash welded joints in high strength steel. Weld. Int. 2004, 18, 436-443. [CrossRef]

20. Lu, P.; Xu, Z.; Shu, Y.; Ma, F. Microstructure and Failure Analysis of Flash Butt Welded HSLA 590CL Steel Joints in Wheel Rims. JOM 2017, 69, 135-143. [CrossRef]

21. Taka, T.T.; Kunishige, K.; Yamauchi, N.; Nagao, N. Hot-rolled Steel Sheet with Excellent Flash Weldability for Automotive Wheel Rim Use. ISIJ Int. 1989, 29, 503-510. [CrossRef]

22. Godefroid, L.B.; Faria, G.L.; Cândido, L.C.; Viana, T.G. Failure analysis of recurrent cases of fatigue fracture in flash butt welded rails. Eng. Fail. Anal. 2015, 58, 407-416. [CrossRef]

23. Saito, T.; Ichiyama, Y. Correlation between welding phenomena and weld defects before and after the start of upsetting: Welding phenomena and process control in flash welding of steel sheet (2nd Report). Weld. Int. 1996, 10, 173-180. [CrossRef]

24. Xi, C.; Sun, D.; Xuan, Z.; Wang, J.; Song, G. Microstructures and mechanical properties of flash butt welded high strength steel joints. Mater. Des. 2015, 96, 506-514. [CrossRef]

25. Ziemian, C.W.; Sharma, M.M.; Whaley, D.E. Effects of flashing and upset sequences on microstructure, hardness, and tensile properties of welded structural steel joints. Mater. Des. 2012, 33, 175-184. [CrossRef]

26. Siddiqui, M.I.H.; Geleta, D.D.; Bae, G.; Lee, J. Numerical Modeling of the Inclusion Behavior during AC Flash Butt Welding. ISIJ Int. 2020, 60, 1-9. [CrossRef]

27. Shibata, H.; Yin, H.; Yoshinaga, S.; Emi, T.; Suzuki, M. In Situ Observation of Engulfment and Pushing of Nonmetallic Inclusions in Steel Melt by Advancing Melt/Solid Interface. ISIJ Int. 1998, 38, 49-56. [CrossRef]

28. Scheller, P.R.; Lee, J.; Yoshikwa, T.; Tanaka, T. Treatise on Process Metallurgy Volume 2: Process Phenomena. In Treatise on Process Metallurgy; Seetharaman, S., Ed.; Elsevier: Oxford, UK, 2013; Volume 2, pp. 119-139.

29. Yin, H.; Emi, T. Marangoni flow at the gas/melt interface of steel. Metall. Mater. Trans. B 2003, 34, 483-493. [CrossRef]

30. Wang, Z.; Mukai, K.; Lee, J. Behavior of fine bubbles in front of the solidifying interface. ISIJ Int. 1999, 39, 553-562. [CrossRef]

31. Mukai, K.; Zeze, M. Motion of fine particles under interfacial tension gradient in relation to continuous casting process. Steel Res. 2003, 74, 131-138. [CrossRef]

32. Matsushita, T.; Mukai, K.; Zeze, M. Correspondence between surface tension estimated by a surface thermodynamic model and number of bubbles in the vicinity of the surface of steel products in continuous casting process. ISIJ Int. 2013, 53, 18-26. [CrossRef]

33. Hong, T.; Debroy, T.; Abu, S.S.B.; David, S.A. Modeling of inclusion growth and dissolution in the weld pool. Metall. Mater. Trans. B 2000, 31, 161-169. [CrossRef]

34. Stachnik, M.; Jakubowski, M. Multiphase model of flow and separation phases in a whirlpool: Advanced simulation and phenomena visualization approach. J. Food Eng. 2020, 274, 109846. [CrossRef]

35. Siddiqui, M.I.H.; Jha, P.K. Assessment of turbulence models for prediction of intermixed amount with free surface variation using CLSVOF method. ISIJ Int. 2014, 54, 2578-2587. [CrossRef]

36. Jakubowski, M.; Wyczalkowski, W.; Poreda, A. Flow in a symmetrically filled whirlpool: CFD modelling and experimental study based on Particle Image Velocimetry (PIV). J. Food Eng. 2015, 145, 64-72. [CrossRef]

37. Jeong, J.; Park, D.; Shim, S.; Na, H.; Bae, G.; Seo, S.-J.; Lee, J. Interfacial tension between SPFH590 microalloyed steel and alumina. Metall. Mater. Trans. B 2019, 51, 690-696. [CrossRef]

38. ANSYS FLUENT Theory Guide 18.2; ANSYS Inc.: Canonsburg, PA, USA, 2017.

39. Cho, D.W.; Na, S.J. Molten pool behaviors for second pass V-groove GMAW. Int. J. Heat Mass Transf. 2015, 88, 945-956. [CrossRef]

40. Engh, T.A.; Simensen, C.J.; Wijk, O. Principles of Metal Refining; Oxford University Press: Oxford, UK, 1992.

41. Sadeghian, B.; Taherizadeh, A.; Atapour, M. Simulation of weld morphology during friction stir welding of aluminum- stainless steel joint. J. Mater. Process. Technol. 2018, 259, 96-108. [CrossRef]

42. Jeong, J.; Park, D.; Shim, S.; Na, H.; Bae, G.; Seo, S.-J.; Lee, J. Prediction of Behavior of Alumina Inclusion in Front of Solid-Liquid Interface in SPFH590 Steel. Metall. Mater. Trans. B Process Metall. Mater. Process. Sci. 2020, 51, 690-696. [CrossRef] 